\title{
Meta Heuristic Optimization Based Renewable Energy Penetration Enhancement in Microgrid with Demand Response
}

\author{
Pothula Jagadeesh $^{\mathrm{a}^{*}}$, M. Mohamed Thameem Ansari ${ }^{\mathrm{b}}$ and M.Saiveerraju ${ }^{\mathrm{c}}$ \\ ${ }^{*}$ Research Scholar, Dept. of Electrical Engineering, Annamalai University, Annamalai \\ Nagar, India. \\ and
}

Assistant Professor, Dept. of EEE, SRKR Engineering College, Bhimavaram, India.

Email: jagadeesh.pothula@gmail.com

${ }^{b}$ Professor, Dept. of Electrical Engineering, Annamalai University, Annamalai Nagar,

India.

Email: ansariaueee@gmail.com

${ }^{c}$ Professor, Dept. of EEE, SRKR Engineering College, Bhimavaram, India.

Email: saiveerraju@yahoo.co.in

\begin{abstract}
A model with a combination of cogeneration and generation photovoltaic power is designed for enhancing the capability of photoelectric absorption. The initial step of the model includes using a "time-of-use price strategy" for guiding the users for changing their electricity consumption patterns to participate in the demand response, hence establishing the demand response model. Next the MATLAB Environment Meta Heuristic Optimization Algorithms of Genetic Algorithm (GA), Particle Swarm Optimization Algorithm (PSO) and Ant Colony Algorithms (ACO) was applied with an aim of reducing the price of the operation of the micro-grid to achieve economic dispatching. The model includes, the constraints of power balance equation, energy storage unit operation, as well as the heat storage. The last part of the research details the results, depicting enhanced levels of consumption of photo-electric energy with the proposed model with comparison of Three Algorithms and also produces economic benefits from using the microgrid.
\end{abstract}

Keywords - Demand Response, time-of-use electricity price, energy storage, cogeneration, Genetic Algorithm (GA), Particle Swarm Optimization Algorithm (PSO) , Ant Colony Optimization Algorithm (ACO).

\section{Introduction}

The renewable consumption energy power generation has progressively become an exploration hot spot in the area of power systems. A large amount of direct light energy exists in tropical countries. At the same time, there is a large heat load demand in these places. In the last few years, the photovoltaic (PV) power generation industry in India has vastly improved. But the PV intermittence power generation has caused the problem of light curtailment. Moreover, the problem of photoelectric absorption has become increasingly serious. Thus, the interaction between the energy and microgrid demand needs to be considered, which can effectively reduce the serious influence of PV light. 
The connection between the power supply and heating systems has been continuously strengthened, and some studies on the optimization of cogeneration microgrid have been reported. An optimization model for multi-time scales of microgrids containing wind power, energy storage, and cogeneration units was proposed in [1]. In [2] and [3], electric boilers were used to uncouple the heat-set restraint and solve the wind power consumption problem in thermal power plant outside its range of the power system. A photothermal power station was introduced in the cogeneration microgrid in [4] to assist in system operation, which provided an efficient way to resolve the PV power generation issue. In [5]-[9], an electro-thermal combined dispatching model was proposed, which used heat storage instruments to increase the elasticity of the cogeneration units. The combination of PV power generation and cogeneration was summarized in [10], [11], which is generally equipped with a certain heat storage capacity to compensate for the instability of PV power output. A summary of the application prospects of an electrothermal system with a large heat storage capacity to deal with the renewable energy consumption problem was presented in [12]. In [13][15], a combined operation system for wind storage was proposed, with a certain schedulability. But the energy storage cost is high and needs to be carefully considered in practical applications. The discussions in the above-mentioned literature on the cogeneration microgrid did not consider demand response in the operation of the microgrid.

In recent years, researches on demand response and energy storage have increased. Large-scale photoelectric consumption can be divided into cost-based consumption and delivery. Promoting local consumption of photo electronics needs to be achieved using price incentives and demand response. Dependent on the combination of the price elasticity matrix and energy storage technology, an optimization model for wind power absorption was constructed in [16], which verified the influence on the demand response wind power consumption. Wind power on-site consumption by switching high-energy load, electricity storage devices, and direct purchase of electricity by users at time-of-use tariffs were promoted in [17]-[19]. The scope of wind power consumption through external delivery was expanded in [20], [21], which is a significant method to resolve the issue of largescale wind curtailment.

The traditional photoelectric consumption model mostly combines PV power generation along with energy storage systems, ignoring the demand response with time-of-use electricity prices. The model does not take into account the role and benefits of the cogeneration device in promoting photoelectric consumption. Therefore, this study discusses the optimization of the microgrid, taking into consideration the demand response and cogeneration system with a heat storage device to promote photoelectric absorption. Firstly, a microgrid system containing a PV power generation system, cogeneration system with heat storage, energy storage, and demand response is proposed, and corresponding mathematical models are established. On this basis, the established mathematical model has settled through the meta heuristic algorithms Genetic Algorithm (GA), Particle Swarm Optimization Algorithm (PSO) and Ant Colony Algorithms (ACO). Lastly, the effectiveness of the suggested optimization operation model is checked via simulation outcomes.

This paper has the major contributions as below:

1) For the PV and cogeneration complex system, an economic dispatching model is created to enhance the photoelectric absorption capability.

2) In the hybrid system model, the "time-of-use electricity price" device is presented to adjust load distribution, which improves the photoelectric absorption level.

3) Considering the model is a blended integer linear programming dilemma, GA, PSO and ACO are utilized to resolve it. The effectiveness of the method for improving photoelectric absorption levels is verified by the analysis of experiment results. 


\section{System Model}

This study establishes an optimized economic dispatching model with PV generator sets, cogeneration units with heat storage, and energy storage systems, as demonstrated in Fig. 1. In this system, both electrical and thermal systems are involved and interact with each other. To promote PV consumption and solve the serious problem of light curtailment, continuously adjusting the mode of operation for energy storage arrangement as well as a cogeneration unit output $(\mathrm{o} / \mathrm{p})$ achieves the best economic benefits and ensures the secure and steady running of the microgrid. Using MATLAB Simulation Software, the test system has been constructed.

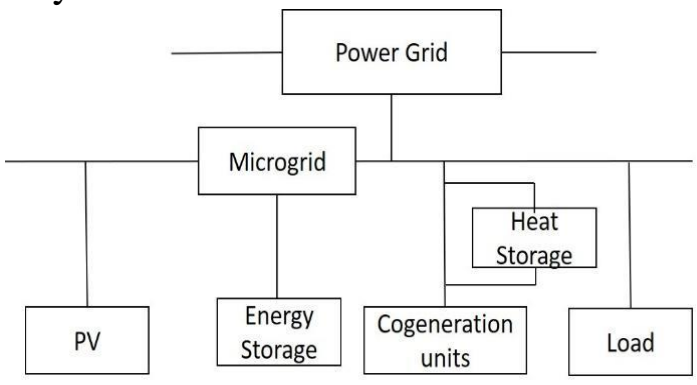

Fig. 1. Diagram of system structure

\section{A. Output Power Model of PV}

PV output power was closely correlated to the intensity of light. PV cells usually run within MPPT: "maximum power point tracking" mode and their o/p power may be represented as [22]:

$$
P V(t)=\zeta(t) \eta M S V \eta \cos \theta(t)
$$

where $\mathrm{P}_{\mathrm{V}}(\mathrm{t})$ indicates the actual output power of $\mathrm{PV}$ for $t$ time; $\zeta(\mathrm{t})$ indicates light intensity of sun at $t$; $\eta_{M}$ denotes efficiency in the MPPT mode; $S_{V}$ is area of a PV panel; $\eta_{V}$ being the efficiency of the PV panel, and $\theta(t)$ indicates the angle of incidence of the moment of illumination at time $t$.

\section{B. Demand Response Model}

This model controls the use of electric energy by changing consumption patters of power by a user, enhancing the power efficiency, and reducing the power loss while satisfying the user's power usage. As per the price of time-of-use electricity, this study looks into the impact of demand-side management on energy use efficiency and promotes photoelectric absorption. The price reduces the electricity demand by a user at the peak time and shifts the demand to the normal or valley time. If necessary, the load is cut during the peak period to alleviate the voltage force, so that the output curve of the power system load becomes more gradual.

This model uses the time-of-use electricity price strategy [20] to promote photoelectric consumption and enhance PV utilization efficiency. Firstly, the load curve is optimized by implementing the "time-of-use" electricity price, spare capacity of load during peak hours is reduced, and the number of switch times of the generator set is reduced. Hence, a demand response model is established.

$$
\begin{aligned}
& E(i i)=\frac{D Q(i) / Q(i)}{D p(i) / p(i)} \\
& E(i j)=\frac{D Q(i) / Q(i)}{D p(i) / p(i)}
\end{aligned}
$$

here $E(i i)$ indicates the "self-elastic coefficient" of the response of the time period at the time $i$, respectively; $E(i j)$ denotes the mutual "elastic coefficient" of the multi-period response at the time $i$ and time $j, i \neq j ; D Q(i)$, as well as $\mathrm{Q}(\mathrm{i})$, are the amounts of change in the load and initial load after implementing the "time-of-use electricity price" of a peak to valley at the time $i$, respectively; $D p(i)$ $\& p(i)$ are the shifts in the electricity price and initial price after implementing the peak-to-valley "time-of-use electricity price" at the time $i$, correspondingly; and $D p(j) \& p(j)$ are the shifts in the electricity price and initial electricity price after implementing the peak to valley "time-of-use 
electricity price" at time $\mathrm{j}$, respectively. From the two types above, the amount of change in the load is:

$$
\Delta \mathrm{Q}(\mathrm{i})=\sum_{i=1}^{T} E(i j) \frac{\Delta P(j)}{P(j)} E(i i)
$$

Where $\mathrm{T}$ indicates the time period.

Depends on the load curve investigation, the fuzzy clustering method of the semi-gradient membership function is utilized to divide the peak-to-valley period. An elastic matrix containing electricity and electricity prices is introduced to describe the price response of the load in each peakto-valley period. Therefore, the load power consumption in each period is obtained after putting the time-of-use power price into practice [17]:

$$
\left[\begin{array}{c}
\Delta Q(1) \\
\Delta Q(2) \\
\vdots \\
\Delta Q(T)
\end{array}\right]=\left[\begin{array}{cccc}
Q(1) & 0 & \cdots & 0 \\
0 & Q(2) & \cdots & 0 \\
\vdots & \vdots & & \vdots \\
0 & 0 & \cdots & Q(T)
\end{array}\right] \mathrm{E}\left[\begin{array}{c}
\Delta P(1) / p(1) \\
\Delta P(2) / p(2) \\
\vdots \\
\Delta P(T) / p(T)
\end{array}\right]
$$

Here E denotes the elastic matrix containing the electricity prices. The energy storage system has dual characteristics and can be used as a load or power source for effective transfer.

\section{Energy Storage and Discharging Model}

In the traditional power production process, the generation and use of electric energy are carried out simultaneously, so the operation and control of the power system are deeply affected. Applying the energy storage system with power system helps solving the real-time balance problem between the power supply and demand side. When this system is widely applied to power generation side, it decreases peak-to-valley gap effectively between day and night, enhances the quality of the power, and facilitates the integration of large-scale renewable energy into a power grid.

This energy storage system has dual characteristics. It can be used as a load or as a power source to properly transfer electric energy. In the microgrid, there is a PV power generation system, which needs to be equipped with a certain energy storage capability. The aim is to balance volatility as well as the randomness of the PV output and improve power quality. During valley load period, this system works as the load to store excess energy. Throughout the peak load period, the system acts as a power source to release the stored electric energy. The energy storage system would have some loss during the dynamic procedure, including the charging \& discharging process. At some time, the energy storage capability, as well as the charging/discharging power, satisfy the following relationship:

Ebat $(\mathrm{t})=(1-\tau)$ Ebat $(\mathrm{t}-1)+[$ uncbat $(\mathrm{t}) \operatorname{Pcbat}(\mathrm{t})-(1-\mathrm{u})$ Pdbat $(\mathrm{t}) / \eta$ dbat $(\mathrm{t})] \mathrm{Dt}$

where $E_{b a t}(t)$ indicates the energy storage capability of energy storage unit at $t$; $\tau$ indicates loss coefficient; $\mathrm{u}$ indicates charging as well as discharging state variable, 1 for charging and 0 for discharging; $\eta c_{\text {bat }}(\mathrm{t}) \& \eta \mathrm{d}_{\mathrm{bat}}(\mathrm{t})$ are charging as well as discharging efficiencies of energy storage unit at $\mathrm{t}$, correspondingly; $\mathrm{P} \mathrm{c}_{\text {bat }}(\mathrm{t}) \& \mathrm{Pd}_{\text {bat }}(\mathrm{t})$ are the charging as well as discharging energy storage unit power at $\mathrm{t}$, correspondingly.

\section{Combined Heat and Power Model}

Volatility of PV output improves the problem of power system regulation. To improve the regulation capacity of the device, a cogeneration device with a heat storage device is added, as demonstrated in Fig.2. If the PV output is large, a space for photoelectric consumption is provided by reducing the cogeneration unit output. If the photoelectric is abandoned, the cogeneration unit increases the forced output triggered via the heat setting. To reduce the forced output, it is essential to compensate 
for the inadequate heating portion. A heat storage unit in "cogeneration unit" may avoid the disadvantage of insufficient heating.

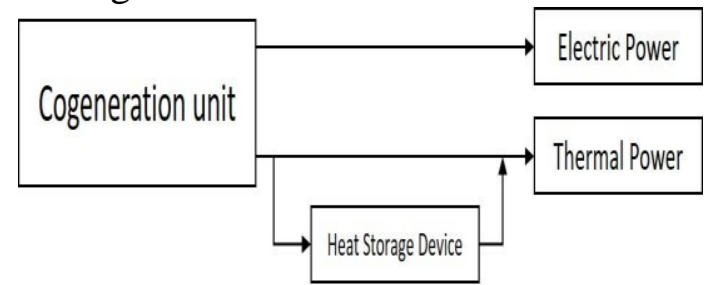

Fig. 2 Combined power and heat unit with heat storage.

However, to meet high heat load demand, the cogeneration unit requires a higher output, which causes serious light curtailment problems. With the direction of the electricity cost strategy during the peak to valley periods, the cogeneration device and heat storage device are used to decouple the heat-set constraint.

\section{Operating Efficiency of Microgrid}

\section{A. Objective Function}

The operation income of microgrid is composed of the income of selling electricity from microgrid to power grid, electricity purchase costs from power grid, and of generation for cogeneration unit. The optimal operation model can be described as:

$$
\begin{gathered}
\text { "min } \mathrm{F}=\mathrm{U}_{\mathrm{bP}}(\mathrm{t}) \mathrm{P}_{\text {bgrid }}(\mathrm{t}) \mathrm{c}_{\mathrm{bP}}(\mathrm{t})-\mathrm{U}_{\mathrm{sP}}(\mathrm{t}) \mathrm{P}_{\text {sgrid }}(\mathrm{t}) \mathrm{c}_{\mathrm{sP}}(\mathrm{t})+\mathrm{C}_{\text {chp }}(\mathrm{t}) \\
\mathrm{C}_{\text {chp }}(\mathrm{t})=\mathrm{aiP}_{\text {chp }}(\mathrm{t})+\mathrm{b}_{\mathrm{i}} \mathrm{P}_{\text {chp }}(\mathrm{t})+\mathrm{c}_{\mathrm{i}} \mathrm{P}_{\text {chp }}(\mathrm{t}) \mathrm{H}_{\text {chp }}(\mathrm{t})+\mathrm{d}_{\mathrm{i}} \mathrm{H}^{2}{ }_{\text {chp }}(\mathrm{t})+\mathrm{e}_{\mathrm{i}} \mathrm{H}_{\text {chp }}(\mathrm{t})+\mathrm{f}_{\mathrm{i}} \text { " }
\end{gathered}
$$

where $\mathrm{F}$ is the operation efficiency of microgrid; $\mathrm{U}_{\mathrm{bP}}(\mathrm{t})$ indicates the state of electricity price to a microgrid from a power grid for $\mathrm{t}\left(0\right.$ means no electricity purchased; 1 otherwise); $\mathrm{P}_{\text {bgrid }}(\mathrm{t})$ denotes the electric power purchased at $t$; $\mathrm{c}_{\mathrm{bP}}(\mathrm{t})$ denotes the unit price of microgrid purchasing electricity from power grid to microgrid at time $t ; U_{S P}(t)$ is a level of selling electricity from power grid to microgrid at $\mathrm{t}\left(0\right.$ means no electricity sold; 1 otherwise); $\mathrm{P}_{\text {sgrid }}(\mathrm{t})$ represents the electric power sold from microgrid to power grid on $\mathrm{t} ; \mathrm{c}_{\mathrm{s}}(\mathrm{t})$ denoting the unit price of selling electricity from microgrid to power grid at $t ; C_{c h p}(t)$ denotes cost of power generation for cogeneration unit at $t ; a_{i}, b_{i}, c_{i}, d_{i}, e_{i}$, $f_{i}$ are the coefficients of the cost function; $P_{c h p}(t)$ indicates the electric power generated by cogeneration unit for $t$, where $\mathrm{H}_{\mathrm{chp}}(\mathrm{t})$ is thermal power emitting on $\mathrm{t}$ in a cogeneration unit.

\section{B. Constraints}

\section{1) Electric Power Constraint balance:}

$$
\mathrm{P}_{\text {bgrid }}(\mathrm{t})-\mathrm{P}_{\text {sgrid }}(\mathrm{t})+\mathrm{P}_{\text {chp }}(\mathrm{t})+\mu_{\text {Pbat }}(\mathrm{t})+\mathrm{P}_{\mathrm{V}}(\mathrm{t})-\mathrm{P}_{\text {load }}(\mathrm{t})=0
$$

where $\mu$ indicates the state of energy storage ( 0 means neither charging nor discharging; 1 means charging; -1 means discharging); $\mathrm{P}_{\text {bat }}(\mathrm{t})$ indicates the charging as well as discharging power of energy storage device at $t ; \mathrm{P}_{\mathrm{V}}(\mathrm{t})$ represents the predicted power of $\mathrm{PV}$ at $\mathrm{t}$, and $\mathrm{P}_{\text {load }}(\mathrm{t})$ indicates power demand of power load at $\mathrm{t}$.

\section{2) Thermal power balance constraint:}

$$
\mathrm{H}_{\text {chp }}(\mathrm{t})+\mathrm{H}_{\mathrm{s}}(\mathrm{t})-\mathrm{H}_{\mathrm{s}}(\mathrm{t}-1)=\mathrm{H}_{\text {load }}(\mathrm{t})
$$

here $H_{s}(t)$ is heat storage capacity for heat storage unit at $t$; and $H_{\text {load }}(t)$ indicates demand of heat load at $\mathrm{t}$.

\section{3) Constraint of Output power generator:}

$$
\mathrm{P}_{\text {chp, min }} \leq \mathrm{P}_{\text {chp }}(\mathrm{t}) \leq \mathrm{P}_{\text {chp, } \max }
$$

where $\mathrm{P}_{\text {chp,max }} \& \mathrm{P}_{\text {chp,min }}$ is upper as well as lower limits of electric power for a cogeneration unit, correspondingly. 


\section{4) Climbing rate constraint of generator:}

$$
\mathrm{R}_{\text {down }} \leq \mathrm{P}_{\text {chp }}(\mathrm{t})-\mathrm{P}_{\text {chp }}(\mathrm{t}-1) \leq \mathrm{R}_{\text {up }}
$$

where $R_{\text {down }}$ and $R_{\text {up }}$ are the minimum as well as maximum uphill rates of cogeneration unit, correspondingly.

5) Energy storage constraints:

$$
\begin{array}{r}
\left\{\sum_{t=1}^{T}(\operatorname{Pcbat}(t)+\operatorname{Pdbat}(t))=00 \leq P \operatorname{cbat}(t) \leq \operatorname{Pcbat}, \max (t) 0 \leq \operatorname{Pdbat}(t) \leq\right. \\
\operatorname{Pdbat,\operatorname {max}(t)}(13)
\end{array}
$$

where $\mathrm{P}_{\text {cbat,max }}(\mathrm{t})$ indicates the maximum charging power for energy storage unit at $\mathrm{t}$; and $\mathrm{P}_{\mathrm{dbat}, \max }$ (t) denotes maximum discharging power of the system at time $t$.

6) Constraints of Heat storage:

$$
\{0 \leq H s(t) \leq H s, \max (t) 0 \leq H f(t) \leq H f, \max (t)
$$

where $\mathrm{H}_{\mathrm{s}, \max }(\mathrm{t})$ represents the maximum heat storage capacity of heat storage unit for $\mathrm{t}$; $\mathrm{H}_{\mathrm{f}}(\mathrm{t})$ indicates capacity of heat release for heat storage unit at $t ; \mathrm{H}_{\mathrm{f}, \max }(\mathrm{t})$ indicates maximum heat release capacity of heat storage unit at $t$.

\section{7) Electricity price constraint:}

$$
\mathrm{P}_{\min } \leq \mathrm{P}(\mathrm{t}) \leq \mathrm{P}_{\max }
$$

here $\mathrm{p}(\mathrm{t})$ indicates power price for $\mathrm{t}$ time; and $\mathrm{P}_{\max }(\mathrm{t}) \& \mathrm{P}_{\min }(\mathrm{t})$ are upper as well as lower power price limits for $\mathrm{t}$, respectively.

\section{8) Demand response constraint:}

$$
\sum_{t=1}^{T} \Delta Q(t)=0
$$

At time $t$, some loads are cut off and transferred without impacting the operation of a power system. The amount of change in load during a cycle is 0 .

\section{Optimization Model}

In the suggested optimization model of microgrid, the cost and benefit of trading between microgrids and large-scale power grid, and the power production cost of cogeneration unit are used as objective parameters. An optimization system includes the equality constraint, a minimum objective function, and many inequality limitations. In the optimization model, Three Optimization algorithms GA, PSO and ACO are used to resolve the issue iteratively, and the present optimal search solution is continuously followed to obtain the global optimal value.

\section{a) Genetic Algorithm (GA)}

The Objective function to minimize the operating cost of microgrid by considering demand response as shown is

$$
\begin{aligned}
\text { Min } \mathrm{F}(\mathrm{P}, \mathrm{St})= & \mathrm{W}_{1} \sum_{i=0}^{T}(P i, P g i, T i)+\mathrm{W}_{2} \sum_{i=0}^{L}(I l(S T l) \\
\text { Subject to, } \quad & \sum P i+P g i=P L i \\
& \mathrm{P}_{\min } \leq \mathrm{P} \leq \mathrm{P}_{\max } \\
& \mathrm{St}_{\min } \leq \mathrm{St} \leq \mathrm{St}_{\max }
\end{aligned}
$$


Following Fig. 3 indicates the flow chart of Genetic Algorithm.

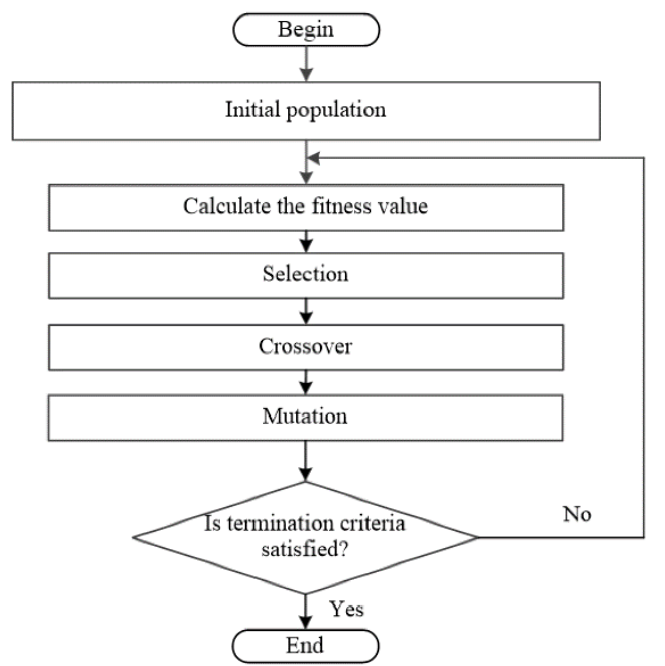

Fig.3 Flowchart of Genetic Algorithm

\section{b) Particle Swarm Optimization Algorithm (PSO)}

In PSO, we begin with a randomized set of individual personal solutions, dubbed a "swarm" of particles. Each particle can be represented as a point in a $\mathbf{J}$-dimensional space, where $J$ is the dimension of individual personal solutions. Each particle then moves through the defined space according to simple mathematical formulae containing its position and velocity. [24] A particle's movement is influenced by three parts - its "momentum", its "memory" of the best position it has been at (the position where the particle had the highest fitness value, called the local best), and the position of the fittest particle (called the global best). This is expected to guide the swarm toward optimal solutions. Note that a particle's fitness value is determined by a problem specific fitness function.

Mathematically, say particle $\mathrm{i}$ is represented as $\quad \mathrm{X}_{\mathrm{i}}=\left(\mathrm{x}_{\mathrm{i} 1}, \mathrm{X}_{\mathrm{i} 2}, \ldots, \mathrm{X}_{\mathrm{i} J}\right)$. Particle $\mathrm{i}$ 's memory of the "best" position it traversed is represented as $\mathrm{P}_{\mathrm{i}}=\left(\mathrm{p}_{\mathrm{i} 1}, \mathrm{p}_{\mathrm{i} 2}, . . \mathrm{p}_{\mathrm{iJ}}\right)$. Let the rate at which the particle i moves (velocity) be given by $\mathrm{Vi}=\left(\mathrm{v}_{\mathrm{i} 1}, \mathrm{v}_{\mathrm{i} 2}, . . \mathrm{v}_{\mathrm{iJ}}\right)$. Let the index of the particle with the best global position be $\mathrm{g}$. Then, in each iteration of the algorithm, particles are manipulated according to Equations 1 and 2.

$$
\begin{aligned}
& \mathrm{v}_{\mathrm{ij}}=\mathrm{w} * \mathrm{v}_{\mathrm{ij}}+\mathrm{c}_{1} * \mathrm{r}_{1} *\left(\mathrm{p}_{\mathrm{ij}}-\mathrm{x}_{\mathrm{ij}}\right)+\mathrm{c}_{2} * \mathrm{r}_{2} *\left(\mathrm{p}_{\mathrm{gj}}-\mathrm{x}_{\mathrm{ij}}\right) \\
& \mathrm{x}_{\mathrm{ij}}=\mathrm{x}_{\mathrm{ij}}+\mathrm{v}_{\mathrm{ij}}
\end{aligned}
$$

In Equation 21, $\mathrm{w} * \mathrm{v}_{\mathrm{ij}}$ represents the momentum of a particle. Here, $\mathrm{w}$ is called the inertia factor. Fig.4 Represents the flowchart of PSO Algorithm. 


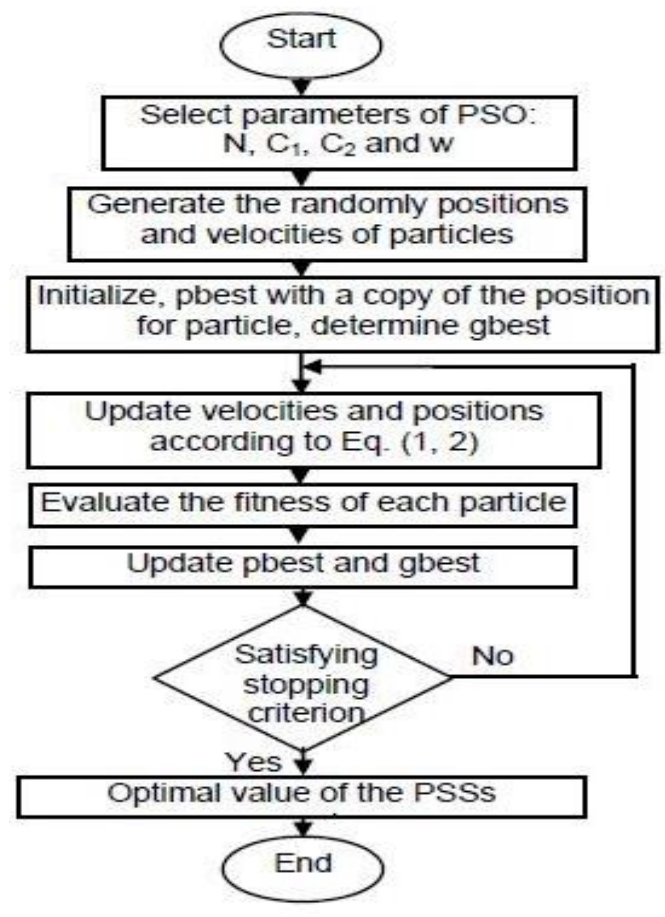

Fig.4 Flowchart of PSO Algorithm

\section{c) Ant Colony Optimization Algorithm (ACO)}

Fig.5 depicts the flow chart. In ACO, updating of pheromones are as follows:

The objective of the modification of the pheromone is to raise the pheromone values for positive solutions and reduce those related to poor solutions. Generally, it can be attained by (i) reducing all pheromone parameters by evaporating the pheromone, (ii) growing the amounts of pheromones correlated to selecting good solutions $S_{\text {upd: }}$

$$
\tau i j \leftarrow(1-\rho) \cdot \tau i j+\rho \cdot \sum_{s \in S u p d \mid c i j \in s} F(s)
$$

here $S_{\text {upd }}$ indicates solution sets which are utilized to update, $\rho \in(0,1]$ indicates the parameters named evaporation rate, $c_{i j}$ indicates finite set of available solution components and $F: S \rightarrow R+0$ represents a function as,

$$
\mathrm{f}(\mathrm{s})<\mathrm{f}\left(\mathrm{s}^{\prime}\right) \Rightarrow \mathrm{F}(\mathrm{s}) \geq \mathrm{F}\left(\mathrm{s}^{\prime}\right), \forall \mathrm{s} \neq \mathrm{s}^{\prime} \in \mathrm{S}
$$

$\mathrm{F}(\cdot)$ denotes generally known as the fitness function. 


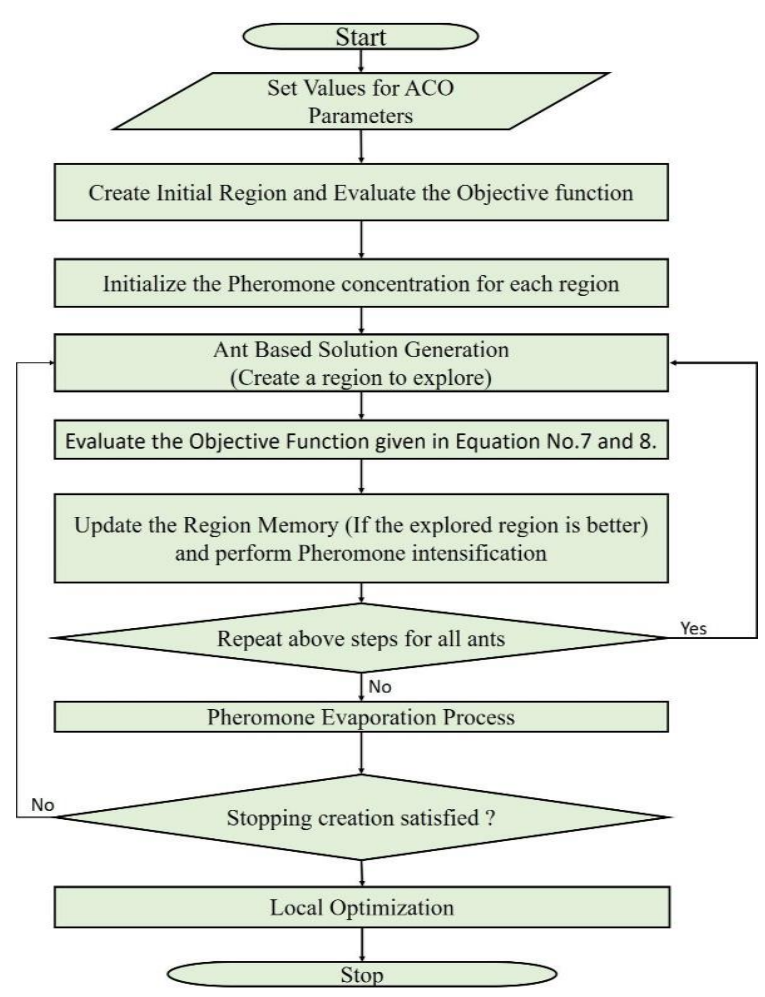

Fig.5 Flowchart of Ant Colony Algorithm

\section{Simulation Results}

The availability of this proposed method and the effect of cogeneration unit can be confirmed with heat storage on photoelectric consumption, the microgrid system including PV power generation units, energy storage systems, and cogeneration generator with heat storage is selected as an illustration example. The PV prediction is shown in Fig. 6. The system uses $20 \mathrm{~kW} \mathrm{PV}$, a typical $900 \mathrm{~kW}$ cogeneration unit, and the maximum charging as well as the power discharging of energy storage device is $10 \mathrm{~kW}$. Typical daily load is used as the demand load. The optimization dispatching period is $T=24$ hours. The unit dispatching time is $T_{d}=1$ hour. The above three meta heuristic optimization algorithms are used in the model.

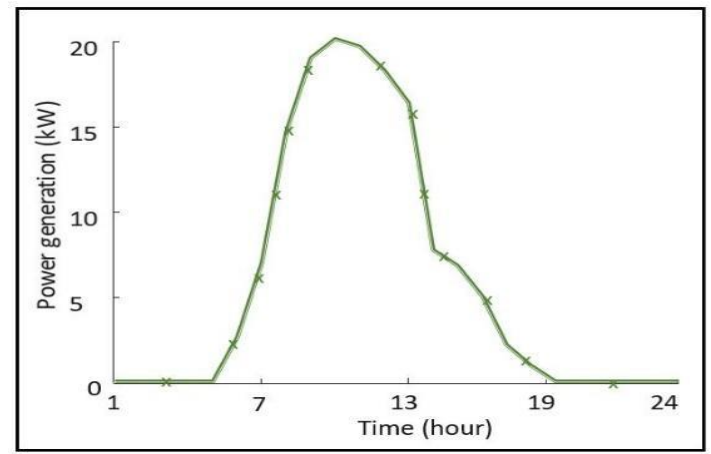

Fig.6 Solar Power Prediction

The division of time and the price of electricity are demonstrated in Table.1. The elastic matrix[23] is as follows:

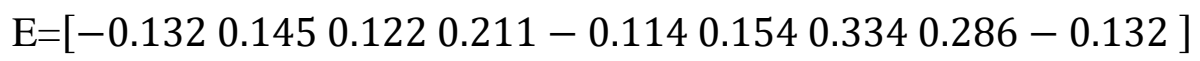


Table.1 Time and Electricity Price division

\begin{tabular}{|c|c|c|}
\hline Time Type & Period & $\begin{array}{c}\text { Price (INR. ₹/ } \\
\text { kWh) }\end{array}$ \\
\hline Valley & $00: 00-08: 00$ & 3.5 \\
\hline Normal & $12: 00-17: 00$ & 7.24 \\
\hline Peak & $08: 00-12: 00,17: 00-21: 00$ & 12.09 \\
\hline
\end{tabular}

In this paper, the simulation evaluation of the established optimization model is performed in the following four operation modes which are mentioned in Table. 2.

Operation mode 1: Traditional photoelectric storage joint operation mode. Both the time-sharing electricity price and cogeneration unit with heat storage do not participate in the optimal dispatching.

Operation mode 2: Based on operation mode 1, the time-sharing electricity price participates in the dispatching, and does not consider the role of cogeneration unit with heat storage.

Operation mode 3: Based on operation mode 1, the cogeneration unit with heat storage participates in the dispatching, regardless of the role of time-of-use electricity price.

Operation mode 4: Based on operation mode 1, there is a joint optimization of time-of-use electricity price and cogeneration unit with heat storage.

The photoelectric consumption for operating mode 1 for three metaheuristic algorithms which are GA,PSO and ACO as shown in Fig.7, for operating mode 2 in Fig.8, for operating mode 3 in Fig.9 and for operating mode 4 in Fig. 10 respectively.

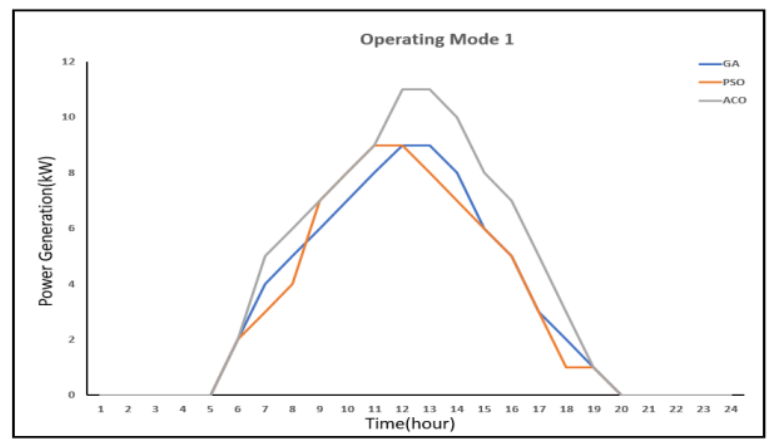

Fig.7 Photoelectric consumption comparison in Operating Mode 1

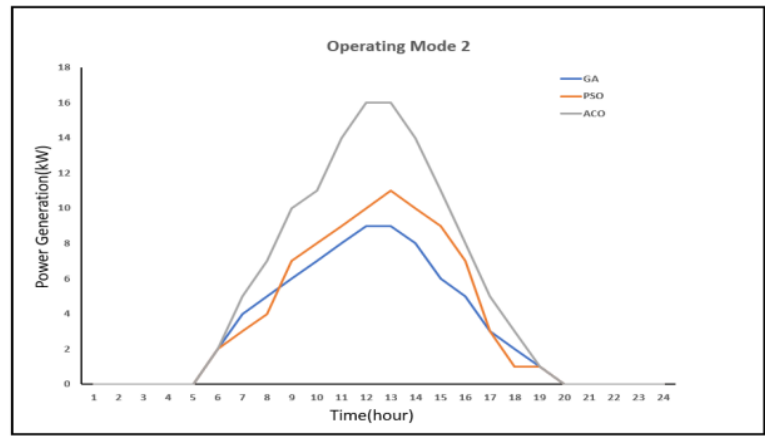

Fig.8 Photoelectric consumption comparison in Operating Mode 2 


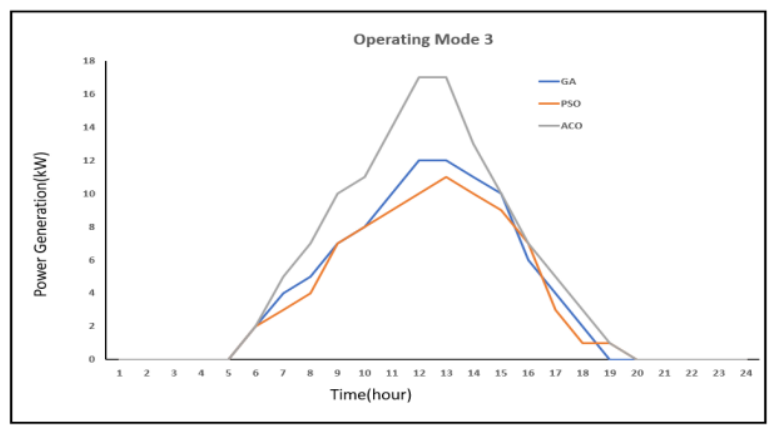

Fig.9 Photoelectric consumption comparison in Operating Mode 3

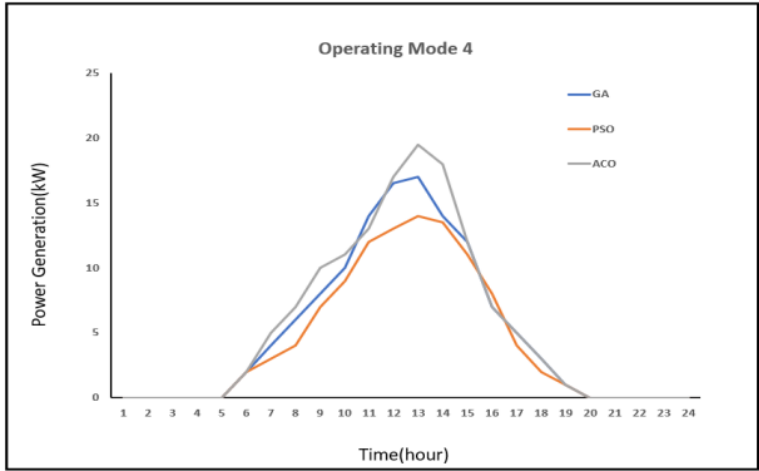

Fig.10 Photoelectric consumption comparison in Operating Mode 4

After the analysis, when the system operates with operation mode 4, the photoelectric consumption capacity is significantly improved, and almost all the discarded photoelectric energy is consumed. From above four figures we can clearly observe among those three meta heuristic optimization algorithms, ACO gives the higher photovoltaic consumption. The outcomes of the three metaheuristic algorithms GA, PSO and ACO suggested calculations are demonstrated in Table.2. By using ACO In operation mode 4, the economic cost of the system can save up to 2,15,03,630 INR, and the photoelectric consumption rate is $97.44 \%$. From the results, the photoelectric, energy storage, cogeneration unit with heat storage, and integrated operation of "time-of-use electricity price" may enhance usage efficiency of light energy \& also save economic costs. The economic costs and photoelectric consumption rates are demonstrated in Table 2.

Table.2 Operating cost and PV Consumption

\begin{tabular}{|c|c|c|c|c|c|c|}
\hline \multirow{2}{*}{ Operation Mode } & \multicolumn{2}{|c|}{ Genetic Algorithm } & \multicolumn{2}{|c|}{$\begin{array}{c}\text { Particle Swarm } \\
\text { Optimization Algorithm }\end{array}$} & \multicolumn{2}{|c|}{$\begin{array}{c}\text { Ant Colony Optimization } \\
\text { Algorithm }\end{array}$} \\
\cline { 2 - 7 } & $\begin{array}{c}\text { Cost } \\
\text { (INR/₹) }\end{array}$ & $\begin{array}{c}\text { PV } \\
\text { Consump } \\
\text { tion Rate } \\
(\%)\end{array}$ & $\begin{array}{c}\text { Cost } \\
(\text { INR/₹) }\end{array}$ & $\begin{array}{c}\text { PV } \\
\text { Consumptio } \\
\text { n Rate (\%) }\end{array}$ & $\begin{array}{c}\text { Cost } \\
\text { (INR/₹) }\end{array}$ & $\begin{array}{c}\text { PV } \\
\text { Consumptio Rate (\%) }\end{array}$ \\
\hline $\begin{array}{c}\text { PV alone without } \\
\text { Time-Sharing } \\
\begin{array}{c}\text { Dispatch and Heat } \\
\text { Storage (Operating } \\
\text { Mode 1) }\end{array}\end{array}$ & $\begin{array}{c}3,05.89,5 \\
69\end{array}$ & 45.43 & $3,05.89,569$ & 45.43 & $2,91,07,318$ & 61.92 \\
\hline
\end{tabular}




\begin{tabular}{|c|c|c|c|c|c|c|}
\hline $\begin{array}{l}\text { PV with time- } \\
\text { sharing dispatch } \\
\text { and without Heat } \\
\text { storage (Operating } \\
\text { Mode 2) }\end{array}$ & $\begin{array}{c}3,03,56,3 \\
41\end{array}$ & 46.04 & $2,99,89,563$ & 55.12 & $2,47,15,775$ & 83.78 \\
\hline $\begin{array}{c}\text { PV with time- } \\
\text { sharing dispatch } \\
\text { along with Heat } \\
\text { Storage without } \\
\text { considering Time of } \\
\text { use (Operating } \\
\text { Mode 3) }\end{array}$ & $\begin{array}{c}2,92,13,6 \\
74\end{array}$ & 60 & $2,98,02,789$ & 56.89 & $2,33,96,949$ & 91.75 \\
\hline $\begin{array}{l}\text { Optimized mode } \\
\text { With Considering } \\
\text { Demand Response } \\
\text { (Operating Mode 4) }\end{array}$ & $\begin{array}{c}2,45,67,6 \\
57\end{array}$ & 85.62 & $2,79,08,786 \mid$ & 71.13 & $2,15,03,630$ & 97.44 \\
\hline
\end{tabular}

When the PV output is high, the electricity load is comparatively small, and the energy storage unit is charged. Simultaneously, the cogeneration unit reduces the output, and the reduced thermal output is provided by the thermal storage device. If the PV output is low, the electricity load is relatively high, and the storage of energy is discharged. If in the non-low valley period, the cogeneration unit increases the output and stores the overdose heat in the heat storage unit. In the period of lightdissipation, to provide absorption space for PV, the cogeneration unit decreases the power generation output and further absorbs the photoelectricity simultaneously by the heat storage device. Fig. 11 displays the change in heat storage device thermal storage in operation mode 4.

Fig.12 presents the alteration in energy storage of the energy storage unit. It may be observed that within the low valley, the system consumes less electricity, and the energy storage device may be treated as the load and then carry out the slave point. During the peak-to-valley period, the system consumes more electricity, and the energy storage device may be treated as the power source for discharging. The energy storage device performs effective charging and discharging, which reduces part of the peak-to-valley gap of power demand and participates in the scheduling of the entire system.

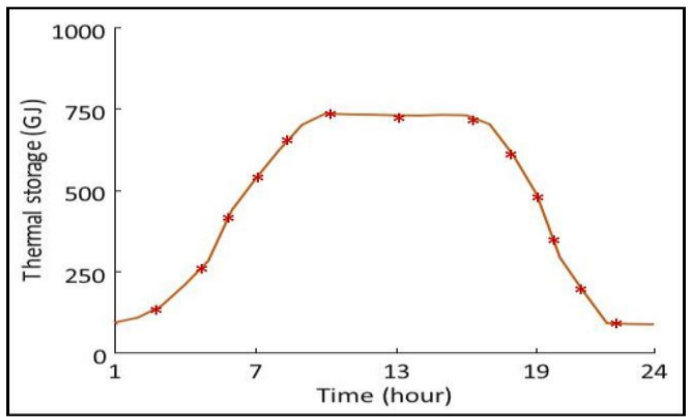

Fig. 11 Change in thermal storage of heat storage device. 


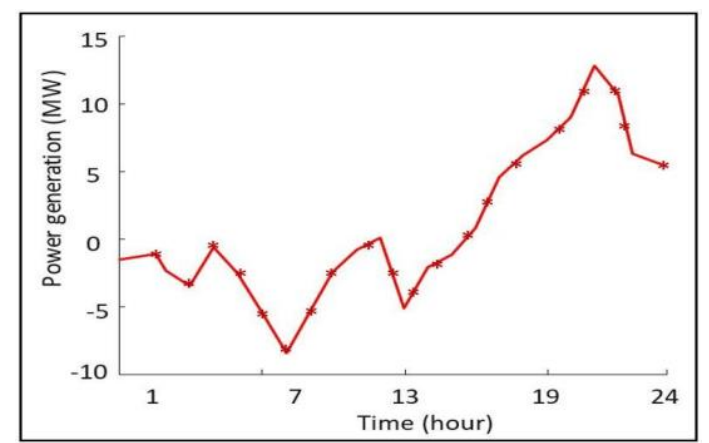

Fig. 12 Change in energy storage of energy storage device.

The mechanism of time-of-use power price and energy storage device is incorporated into the photoelectric consumption model, which is also combined with the cogeneration unit. Fig. 13 below demonstrates the Load Demand. When mechanism of "time-of-use electricity price" along with the energy storage unit is depicted, the gap between peak to valley of load demand decreases.

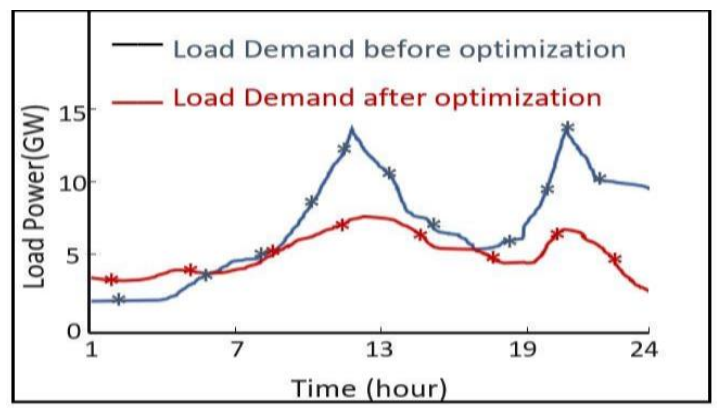

Fig. 13 Daily load demand.

\section{CONCLUSION}

A joint system was suggested in the paper for PV, energy storage, and cogeneration units with thermal storage devices. The demand response is considered to depend on time-of-use tariffs. By MATLAB simulation verification, the following conclusions are found while comparing three meta heuristic optimization algorithms.

1) ACO Suggested model will give higher photovoltaic generation penetration in economical when compare with Genetic Algorithm and Particle Swarm Optimization.

2) In comparison with the conventional combined photoelectric storage operation mode, the proposed scheme considering the cogeneration unit with heat storage and the time-of-use electricity price can absorb more PV power. This operation mode greatly increases the photoelectric consumption rate and reduces operation costs.

3) The "time-of-use electricity price" along with the storage energy unit may help enhance load distribution and decrease gap in the maximum with minimum load.

4) The heat storage unit may use the heat load to adjust the capacity of the cogeneration unit, which can be reflected in the microgrid revenue brought about by peak clipping and valley filling.

In-depth research is also needed in subsequent studies. Ways of choosing heat storage capacity of devices require to be considered to match the PV power production, energy storage device, and cogeneration unit.

\section{Appendix}

PV Power Generating Capacity: 20MW 
Cogeneration unit Capacity: 900MW

Storage System Capacity: 10MW

Dispatching Time Period Taken for Optimization: 24 hours

Unit Dispatching time Taken for optimization: 1 hour

\section{References}

[1] Q. Ai and R. Hao, "Key technologies and challenges for multi-energy complementarity and optimization of the integrated energy system, " Automation of Electric Power Systems, vol. 42, no. 4, pp. 2-10, Feb. 2018.

[2] Q. Li, L. Feng, Y. Xu et al., "Accommodation mode of wind power based on water source heat pump technology," Automation of Electric Power Systems, vol. 36, no. 17, pp. 25-27, Sept. 2012.

[3] Q. Lv, H. Jiang, T. Chen et al., "Wind power accommodation by combined heat and power plant with electric boiler and its national economic evaluation," Automation of Electric Power Systems, vol. 38, no. 1, pp. 6-12, Jan. 2014.

[4] E. Du, N. Zhang, C. Kang, et al., "Reviews and prospects of the operation and planning optimization for grid integrated concentrating solar power, "Proceedings of the CSEE, vol. 36, no. 21, pp. 5765-5775, Nov. 2016.

[5] W. Wang, L. Yang, L. Wang, et al., "Optimal dispatch of integrated electricity-heat energy system considering heat storage characteristics of heating network," Automation of Electric Power Systems, vol. 42, no. 21, pp. 45-52, Nov. 2018.

[6] Q. Lv, T. Chen, H. Wang, et al., "Analysis on the peak-load regulation ability of cogeneration unit with heat accumulator," Automation of Electric Power Systems, vol. 38, no. 11, pp. 34-41, Jun. 2014.

[7] Z. Li, W. Wu, M. Shahidehpour et al., "Combined heat and power dispatch considering pipeline energy storage of district heating network," IEEE Transactions on Sustainable Energy, vol. 7, no. 1, pp. 12-22, Jan. 2016.

[8] Z. Li, W. Wu, J. Wang et al., "Transmission-constrained unit commitment considering combined electricity and district heating networks, " IEEE Transactions on Sustainable Energy, vol. 7, no. 2, pp. 480-492, Apr. 2016

[9] X. Chen, C. Kang, M. O'Malley, et al., "Increasing the flexibility of combined heat and power for wind power integration in China: modeling and implications," IEEE Transactions on Power Systems, vol. 30, no. 4, pp. 1848-1857, Jul. 2015.

[10] S. H. Madaeni, R. Sioshansi, and P. Denholm, "Estimating the capacity value of concentrating solar power plants with thermal energy storage: a case study of the southwestern United States, ”IEEE Transactions on Power Systems, vol. 28, no. 2, pp. 1205-1215, May 2013.

[11] R. Sioshansi and P. Denholm, "The value of concentrating solar power and thermal energy storage," IEEE Transactions on Sustainable Energy, vol. 1, no. 3, pp. 173-183, Oct. 2010.

[12] Y. Cui, Z. Chen, G. Yan, et al., "Coordinated wind power accommodating dispatch model based on electric boiler and CHP with thermal energy storage, "Proceedings of the CSEE, vol. 36, no. 15, pp. 4072-4080, Aug. 2016.

[13] F. Xu, Y. Min, L. Chen et al., "Combined electricity-heat operation system containing large capacity thermal energy storage," Proceedings of the CSEE, vol. 34, no. 29, pp. 5063-5072, Oct. 2014. 
[14] X. Wu, X. Wang, J. Li et al., "A joint operation model and solution for hybrid wind energy storage systems," Proceedings of the CSEE, vol. 33, no. 13, pp. 10-17, May 2013.

[15] G. Yan, J. Liu, Y. Cui, et al., "Economic evaluation of improving wind power scheduling scale by an energy storage system," Proceedings of the CSEE, vol. 33, no. 22, pp. 45-52, Aug. 2013.

[16] B. Aluisio, M. Dicorato, G. Forte, et al., "Hybrid energy storage system optimization for improving wind power integration, " in Proceedings of the 2016 Power Systems Computation Conference on Power Systems Computation Conference (PSCC), Genoa, Italy, Aug. 2016, pp. $1-9$.

[17] Y. Song, Z. Tan, H. Li et al., "An optimization model combining generation side and energy storage system with demand-side to promote accommodation of wind power," Power System Technology, vol. 38, no. 3, pp. 611-615, Mar. 2014.

[18] W. Ruan, B. Wang, Y. Li et al., “Customer response behaviour in time-of-use price," Power System Technology, vol. 36, no. 7, pp. 86-93, Jul. 2012.

[19] Q. Cui, X. Wang, and W. Wang, "Stagger peak electricity price for heavy energy-consuming enterprises considering improvement of wind power accommodation," Power System Technology, vol. 39, no. 4, pp. 946-952. Apr. 2015.

[20] W. Zhang, X. Wang, X. Wu et al., "An analysis model of power system with large-scale wind power and transaction mode of direct power purchase by large consumers involved in system scheduling," Proceedings of the CSEE, vol. 35, no. 12, pp. 2927-2935. Jun. 2015.

[21] W. Gu, Z. Wu, R. Wang et al., "Multi-objective optimization of combined heat and power microgrid considering pollutant emission, ” Automation of Electric Power Systems, vol. 36, no. 14, pp. 177-185, Jul. 2012.

[22] G. W. Ault, K. R. W. Bell, and S. J. Galloway, "Calculation of economic transmission connection capacity for wind power generation, " IET Renewable Power Generation, vol. 1, no. 1, pp. 61-69, Mar. 2007.

[23] C. Dou, X. Zhou, T. Zhang and S. Xu, "Economic Optimization Dispatching Strategy of Microgrid for Promoting Photoelectric Consumption Considering Cogeneration and Demand Response," in Journal of Modern Power Systems and Clean Energy, vol. 8, no. 3, pp. 557-563, May 2020, doi: 10.35833/MPCE.2019.000214.

[24] A. Raghavan, P. Maan and A. K. B. Shenoy, "Optimization of Day-Ahead Energy Storage System Scheduling in Microgrid Using Genetic Algorithm and Particle Swarm Optimization," in IEEE Access, vol. 8, pp. 173068-173078, 2020, doi: 10.1109/ACCESS.2020.3025673. 